\title{
ENKELE EKONOMIESE ASPEKTE VAN DIE OLIEKRISIS
}

\section{INLEIDING}

Die energiekrisis, brandstofrantsoenering, beperkings op reise, Arabiese afpersing, werkloosheid, ekonomiese resessie, stagnasie met inflasie en laer lewenstandaarde was in die jongste tyd van die belangriskte internasionale nuusberigte.

Alhoewel al hierdie aspekte die ernstige aandag van die internasionale gemeenskap in beslag geneem het, word die oliekrisis, wat sedert Oktober 1973 bestaan, toe die Arabiese state op oliebeperkings besluit het, op die oomblik in die meeste lande as van die allergrootste belang beskou.

Onderwyl daar oor die Weste reeds spanning bestaan het as gevolg van die Arabiese oliebeperkings, is 'n verdere skokberig op 24 Desember 1973 ontvang toe die olieproduserende state van die Persiese Golf besluit het om die prys van ru-olie vanaf die begin van 1974 van $\$ 5,11$ tot $\$ 11,65$ per 42 gallon vat te verhoog. Die somberheid het op Kersdag ietwat verlig toe die ministers van nege Arabiese state aangekondig het dat instede van hul olieproduksie in Januarie met 5 persent te verminder hul dit met 10 persent gaan verhoog.

Die oliekrisis het ' $n$ aantal botsende belange en partye toe in dieselfde hoek gedryf. Hier word veral gedink aan Nederland wat saam met Suid-Afrika, Portugal en die V S A op dieselfde wyse aan ' $n$ algehele olieboikot onderwerp is. Tog was die olieverbod op die V S A nie so waterdig nie want amptenare van die V S A verklaar dat die V S A tot onlagns in staat was om meer olie as wat verwag is in te voer aangesien die Arabiese olieboikot nie ten volle geslaagd was nie. Die Arabiere het hulle olieproduksie klaarblyklik nie met 25 persent besnoei nie, soos hulle voornemens was. Die totale tenkvragte by die ses Midde-Oosterse hawens het gedurende die laaste drie maande van 1973 glo met 31 persent op dié van 'n jaar vroeër toegeneem. Die internasionale oliemaatskappye het heelwat ru-olie vanaf Iran, Indonesië en Nigerië na die V S A geherkanaliseer om sodoende gedeeltelik vir die verlies van Arabiese olie te kompenseer. (Hierdie ervaring het weer geleer dat boikotte nie effektief toegepas kan word nie.)

In hierdie artikel word kortliks gelet op enkele van die vernaamste ekonomiese aspekte van die oliekrisis.

\section{AFHANKLIKHEID VAN OLIE}

Suid-Afrika is in die gelukkige posisie dat ongeveer 80 persent van sy energiebehoeftes deur steenkool voorsien word. Olie voorsien in 
20 persent van die land se energiebehoeftes waarvan Iran en Sasol die helfte voorsien terwyl die Arabiese state in die verlede die balans voorsien het. Gevolglik sal 'n algehele olieverbod deur die Arabiese state energievoorrade in Suid-Afrika met slegs 10 persent verminder.

Volgens Prof R K Dutkiewicz, direkteur van die Energiebenuttingseenheid aan die Universiteit van Kaapstad en voorheen hoof van die beplanningsafdeling van Evkom sal steenkool teen die jaar 200074 persent van Suid-Afrika se elektrisiteit produseer, kernkrag 14 persent en die res deur hidro-elektriese skemas, insluitende die Cabora Bassa se 8 persent bydrae. Hierdie vooruitskatting is gebaseer op prysoorwegings en die geloof dat steenkool die goedkoopste energiebron sal wees.

Dr Louw Alberts, vise-president van die Atoomkragraad, daarenteen, meen dat elektrisiteit in S A tot 'n groot mate deur kernkragsentrales voorsien sal word terwyl steenkool vir die produksie van gas, olie en petrol gebruik sal word.

Die V S A en Japan is vir hul energie respektiewelik vir 50 persent en 75 persent van olie afhanklik, Wes-Duitsland vir 60 persent, Brittanje vir 48 persent, Frankryk vir 72 persent en Italië vir 80 persent.

Alhoewel die boikot Europa en Japan die nadeligste getref het, ly die V S A ook daaronder. Die V S A produseer daagliks 11 miljoen vate olie en is tans die grootste enkel olieprodusent ter wêreld. Tog voorsien hy nie in sy daaglikse behoeftes van 17,3 miljoen vate nie. Om hierdie tekort te voorsien word sowat 1 miljoen vate daagliks van die Midde-Ooste alleen ingevoer. Gedurende die tweede kwartaal van 1973 het die V S A sowat 16 persent van sy olie vanaf Arabiese state ingevoer en na raming sal die V S A teen 1980 waarskynlik ongeveer die helfte van sy oliebehoeftes invoer waarvan sowat $2 / 3$ waarskynlik vanaf die Midde-Ooste sal kom. Die V S A het groot belange in Arabiese Olieproduserende State waar Amerikaanse meer as $\$ 5000$ miljoen belê het. Die opbrengs op hierdie beleggings wat jaarliks in die V S A terugvloei beloop $\$ 2000$ miljoen wat gelykstaande is aan 20 persent van die wins op die totale Amerikaanse buitelandse beleggings.

Die Arabiese olieverbod tref Botswana, Lesotho en Swaziland in dieselfde mate as vir die Republiek van Suid-Afrika omdat hulle geheel en al van die Republiek se olievoorsiening afhanklik is. 'n Arabiese olie-afvaardiging bestaande uit vyf lede van die Federale Nasionale Vergadering van die Arabiese Republieke het op 14 Januarie 1974 in Botswana aangeland op 'n sewedaagse besoek na strategiese plekke in die land en vir konsultasies met die kabinet van Botswana. Hier- 
vandaan het hulle na Lesotho en Swaziland vertrek. Ander lande wat op hul lys verskyn is Zambi;, Tanzanië, Kenia en Somaliland.

Alhoewel die samesprekings in die grootste geheim plaasgevind het, word algemeen aanvaar dat die Arabiere hiermee hulle invloedsfeer na die suide wil uitbrei en dat Botswana die afvaardiging waarskynlik meegedeel het dat 'n voortgesette olieboikot teen Suid-Afrika ernstige gevolge op Botswana, Lesotho en Swaziland sal hê. Gedurende die besoek is Botswana, na verneem word, die versekering gegee van voorgesette olievoorrade om die land se minerale-ontwikkeling te verseker en dat die oliewapen slegs teen regerings gerig is wat die Arabiese saak nie goedgesind is nie. Die metodes waarop voortgesette olievoorsiening sal plaasvind is nie uiteengesit nie, aangesien dit tegnies van aard is en verdere studie vereis.

Die res van Afrika is deur ander afvaardigings besoek en almal het een doel, naamlik om dankbaarheid te betuig vir die steun van die Arabiese saak en om vas te stel waar en hoe die Arabiere kan help. Die produksie en pryse van olie het gedurende di? afgelope paar jaar sodanig toegeneem dat die olie-inkomste van die O P E C - lande verdubbel het. In 1972 byvoorbeeld het Libië, met 'n bevolking van slegs 2 miljoen, $\$ 1600$ miljoen, of $\$ 800$ per capita verdien terwyl Kuweit, met 'n bevolking van slegs $830000, \$ 1700$ miljoen of $\$ 2040$ per capita vı rdien het. Saudi Arabië produseer tans sowat 8 miljoen vate daagliks en dit word verwag dat die produksie teen 1975 10 miljoen en teen 198020 miljoen vate sal beloop. Inkomste uit olie maak 90 persent van hierdie land se begrotingsontvangstes en 95 persent van sy verdienste aan buitelandse valuta uit.

\section{MOTIEWE VIR OLIEKRISIS.}

Met hul jongste oliebeleid wil die Arabiere dit duidelik stel dat die Weste se werklike belang by die Arabiere geleë is. Sjeik Ahmed Zaki Yamani, Saudi Arabie se olieminister, het in hierdie verband die volgende beweer: "We do not wish the nations of the world to suffer . . We only intended to attract world attention to the injustice that befell the Arabs." Hulle meen dus dat die Weste te veel ten gunste van Israel kan kies en dat die oliebeperkings die Weste tot ander insigte sal bring. Vanuit hul sterk markposisie is die Arabiese lande in staat tot 'n monopolistiese optimisasie van hul pryse en kan hulle ook die uitputtingstempo van hul reserwes bepaal. Hierdeur word nie alleen hulle welvaart verhoog nie maar vind die ekploitasie volgens hulle eie tydtafel en nie die van die verbruikers plaas nie. Suid-Afrika, wat so ryklik met mineraalbronne bedeeld is, beklee in hierdie verband dieselfde magsposisie veral ten opsigte van goud, uraan en platina. 
Oor die motiewe vir die drastiese verhoging van die oliepryse bestaan daar onder diplomate verskil van mening. Sommige meen dat dit suiwer materialistiese gulsigheid is terwyl ander weer meen dat die sogenaamde "grand design" wat Sjah Pahlavi van Iran ontwerp het, daarop gemik is om 'n markprys vir olie te ontwikkel gebaseer op die koste van ander vorme van energie. Die Sjah verklaar: "This will correspond to the minimum price that we will have to pay either to get shale oil or liquefaction of coal or gasification of coal. Eventually we will have .... assurances and counterassurances for the cost of energy upon which future world industries could be based. . As to the industrial world, I think that the era of their terrific progress and even more terrific income and wealth based on cheap oil is gone. Eventually, they have to tighten their belts.

'n Iranse regeringsamptenaar het in hierdie verband ook verklaar dat Iran slegs in die verdienste van geld uit olie geinteresseerd is. Sy olieverkope sal nie deur politieke oorwegings beïnloed wurd nie en sal aangewend word om Iran se ontwikkeling te stimileer. By geleentheid het die Sjah dan ook verklaar dat hy teen die gebruik van die olie as 'n politieke wapen is omdat dit in vredestyd 'n gevaarlike en anargistiese stap is.

Iran se standpunt is dat pryse van basiese materiaal soos yster, sement en rubber waaraan hy 'n groot behoefte het, die afgelope 2 tot 3 jaar met 300 persent gestyg het en dat die jongste olieprysstyging ' $\mathrm{n}$ gevolg van inflasie in die industriële wêreld is.

Teen huidige verbruikskoerse besit die wêreld nog vir sowat 35 jaar voldoende olie. Indien olieverbruik binne die volgende dekade verdubbel - soos die geval was die afgelope dekade - en geen verdere oliebronne ontdek word nie, sal die wêreld se olievoorraad na verwagting selfs binne die volgende 11 jaar uitgeput kan raak. Die O P E C - state voel dat dit onbillik is om toe te laat dat hul hoofbron van inkomste binne afsienbare tyd sal verdwyn terwyl die nywerheidslande van die wêreld met steenkool en ander bronne energie vir 400 jaar het.

Die Arabiese sjeiks en konings wat die Persiese Golf se olie in sowel prys as in aanbod beheer is basies konserwatiewe Moslems, is niekommunisties en in ideologie basies pro-Westers. Hul mark lê nie in Rusland nie omdat laasgenoemde 'n mededinger op die wêreldmark is en vir die afsienbare toekoms sal bly. Verder besef hulle dat chaos in die Westerse wêreld hulself baie nadelig kan tref.

Die Golfprodusente het geen langtermynbelang in die skep van ernstige olietekorte in die V S A of ander geïndustrialiseerde lande nie 
omdat dit sal lei tot ' $n$ dramatiese beweging ten gunste van mededingende energie-selfvoorsiening. So ' $n$ beweging sal vir die Arabiese wêreld fataal wees omdat olie hul enigste uitvoerproduk is. Indien hulle hierdie mark verloor sal dit hul verpligtinge ten opsigte van ekonomiese uitbreiding baie jare vertraag.

4. ENKELE EKONOMIESE GEVOLGE VAN DIE OLIEKRISIS.

4.1 Met die jongste olieprysverhogings verwag die ses Persiese Golflande vir 1974 ' $n$ inkomste van $\$ 60000$ miljoen uit olieinkomste in vergelyking met $\$ 16000$ miljoen in 1973 - 'n toename dus van 275 persent. Iran alleen verwag 'n verdienste van $\$ 24000$ miljoen wat 250 persent meer is as in 1973.

4.2 Die geïndustrialiseerde lande van die Organisasie vir Ekonomiese Samewerking en Ontwikkeling (O E S O) en die ontwikkelende lande se koste aan olie-invoere word vir 1974 respektiewelik op $\$ 40000$ miljoen en $\$ 5000$ miljoen hoër as vir 1973 beraam. Volgens skatting sal S.A. vanjaar sowat R700 miljoen meer vir ongeveer dieselfde hoeveelheid olie as verlede jaar moet betaal.

4.3 As gevolg van die hoër brandstofuitgawes sal die welvarende nasies nou ook minder geld beskikbaar hê om ontwikkelingshulp aan die armer lande beskikbaar te stel. Die totale buitelandse hulp aan die wêreld se arm lande word vir 1974 op $\$ 4500$ miljoen beraam, maar met die jongste verdubbeling in die Golfoliepryse sal die hele bedrag in die sakke van die olieprodusente vloei. Die V S A het reeds te kenne gegee dat hy sy hulp aan 41 Afrikalande gaan staak as gevolg van buitelandse valuta wat nou vir hoër oliepryse benodig word.

4.4 Gedurende Desember 1973 is ' $n$ Afro-Arabiese bank in die Midde-Ooste onder leiding van President Sadat van Egipte gestig om ontwikkelingshulp aan Afrikalande te verleen en hulle te help om die oliekrisis te bowe te kom. Elke Arabiese land sal 'n deel van die miljoene wat uit die verhoogde oliepryse gehaal word by die nuwe bank inbetaal wat reeds met 'n kapitaal van R50 miljoen begin het.

4.5 Die internasionale motorbedryf met al sy vertakkinge sowel as die petrolverwante bedrywe is onmiddellik deur die olieboikotgetref. Mnr. George Ward, besturende direkteur van Peugeot, Automabiles South Africa, meen dat minstens 4 motorfabrieke as gevolg van die oliebeperkings teen die einde van 1975 in 
Suid-Afrika sal moet sluit. Mnr. Doug Kitterman, besturende direkteur van Ford, het direk na die aankondiging van die petrolbeperkinge aangekondig dat 10 motorfabrieke teen die jaar tagtig nie meer in Suid-Afrika sal wees nie. Slegs die sterkste fabrieke sal in die skerp mededingende mark kan voortbestaan.

4.6 'n Kritiese ontleding van die invloed wat petrolprysverhogings op die koste van meeste produkte het dui daarop dat die koste van olie inderdaad maar ' $n$ relatiewe geringe aandeel daarvan uitmaak. Vir die private motoreienaar verteenwoordig petrol maar slegs 16 persent van die koste om 'n motor op die pad te hou, terwyl petrol in die verbruikersprysindeks maar 'n faktor van slegs 2,79 persent is. In die boerderybedryf verteenwoordig, brandstof slegs 4,8 persent van alle plaasuitgawes. Disproporsionele prysstygings onder die dekmantel van hoër afleweringskoste as gevolg van die petrolprysverhogings kan dus nie sonder meer aanvaar word nie. Verhoogde oliepryse kan hoogstens 2 persent tot ons huidige inflasiekoers wat reeds meer as 10 persent beloop, bydra. Na raming sal die nuwe oliepryse die inflasiekoers in Europa met ongeveer 3 persent verhoog.

4.7 Die ekonomiese vooruitskatting vir die wêreld was nog nooit voorheen so somber as juis vir 1974 nie. Alhoewel deskundiges nie oor alle punte saamstem nie is hulle eenstemmig dat 'n afswaai in die wêreld se drie sterkste ekonomieë, naamlik dié van die V S A, Japan en Wes-Duitsland sal voorkom en dat die inflasiekoers hoog sal bly. Voorspellings oor die ekonomiese groei vir 1974 wissel van 0 tot 2 persent vir die $V S A \in n$ Wes-Duitsland; in Japan is selfs 'n negatiewe groei op een stadium voorspel indien die olietoevloei na Japan nie aansienlik verbeter nie. Tekens van 'n ekonomiese afswaai in genoemde lande was reeds waarneembaar voor die Yom Kippuroorlog, maar die oliebeperkings sal 'n verdere negatiewe uitwerking hê. Alle voorspellings word natuurlik deur die olieboikot beînvloed maar geen ernstige internasionale resessie word verwag nie Otto Eckstein van die Harvard Universiteit voorspel vir 1974' 'n reële groei van 1,6 persent vir die V S A op voorwaarde dat die olie boikot teen die V S A teen Maart of April vanjaar beëindig word. Meeste ekonome is dit eens dat die V S A binne die volgende ses maande 'n resessie sal hê of op die rand daarvan sal wees. Na verwagting sal 'n Amerikaanse resessie nie langer as 6 maande duur nie. Biljoene dollars sal in die komende maande in energie-uitbreiding en massavervoer investeer word wat hoër wins, meer werkgeleenthede en beter lewenstandaarde sal skep. 
4.8 'n Ernstige en langdurige ressesie in die V S A, Europa en Japan kan Suid-Afrika en ander grondstofproduserende lande baie nadelig tref want daardeur sal die grootste grondstofmark 'n gevoelige slag kry. 'n Japanese nies kan maklik 'n Antarktiese sneeustorm laat ontketen. Dreigende resessies in die Weste is beslis ook nie in die beste belang van Arabiese finansiële bates wat in die Weste besit word nie.

4.9 Die olieboikot het 'n onregstreekse invloed op die sakeklimaat in Suid-Afrika wat investeringsbesluite kan benadeel. Brandstofrantsoeneringsmaatreëls het reeds 'n nadelige uitwerking op die motor- en verwante bedrywe. Die sielkundige klimaat wat uit onsekerheid gebore is kan persoonlike besparing aanmoedig ten koste van verbruiksbesteding.

4.10 Afgesien van die algemene inflasionistiese aspekte van die olietekort mag dit ook meebring dat ons nie die nodige buitelandse kapitaaltoevloei vir vaste investering kry wat so dringend benodig word vir ekonomiese uitbreiding nie; dat ons buitelandse afsetgebiede benadeel word en dat ons binnelandse werkloosheid mag toeneem. Mnr R du Plessis, direkteur van die Motornywerhede Federasie verwag byvoorbeeld dat tussen 20 en 30 persent van die 60000 petroljoggies gedurende 1974 ontslaan sal word.

4.11 Onder die huidige omstandighede kan ons baie dankbaar wees oor ons goudmynbedryf want solank as wat die oliekrisis duur sal die goudprys styg of stewig vertoon en dit verskans ons redelik teen ernstige betalingsbalanstekorte waarmee meeste lande vanjaar gaan worstel. Die olietekort kan ook lei tot mededingende devaluasies wat tot goud se voordeel strek. 'n Hoër goudprys bring mee goedkoper oliepryse in terme van goud. Die moontlikheid dat die Arabiere in die toekoms goud as enigste betaling vir olie, instede van ander onstabiele geldeenhede mag eis, is ook nie uitgesluit nie.

4.12 Vir Suid-Afrika beteken al hierdie gebeure nie noodwendig 'n resessie vir 1974 nie. Regeringsuitgawes styg sterk, landbou sal 'n positiewe bydrae maak en heelwat industriële uitbreidingsprogramme is op hierdie stadium reeds -so ver gevorder dat dit nie meer teruggetrek sal word nie. In regeringskringe is die hoop gekoester dat die ekonomiese groei vanjaar 7 persent en selfs 8 persent sal wees wat 'n groot verbetering op verlede jaar se 5 persent en 1972 se 3,3 persent sal wees.

4.13 Die hoë olieprys het ook 'n aantal positiewe aspekte. Eerstens help dit om die vraag na brandstof te verminder - 'n aansienlike hoeveelheid is in die verlede verkwis. Tweedens, stimuleer 
dit kapitaalbesteding in die breë energieterrein wat 'n belangrike langtermyn plusfaktor vir die ekonomieë van die wêreld beteken.

\section{MOONTLIKE ALTERNATIEWE KRAGBRONNE}

Die huidige krisis het Westerse lande onder die besef gebring van hoe noodsaaklik dit is om alternatiewe kragbronne te ontwikkel. Wetenskaplikes in die E E G - lande ondersoek vir etlike jare reeds die potensiaal van kernenergie wat tot op hierdie stadium slegs vir die opwekking van elektrisiteit gebruik is. Die oprigting van 'n kernkragsentrale neem sowat 4 jaar.

Die vraag ontstaan in hoeverre die tegniek in staat sal wees om substitute vir olie te lewer? Op hierdie stadium bestaan daar weining. Dit is ontstellend veral omdat 'n ernstige olietekort in die jare tagtig dreig. Die huidige probleme kan dus as 'n voorloper van die dreigende tekort gesien word. Onder hierdie omstandighede is energiedeskundiges wat voor die krisis ook nie stil gesit het nie nou tot aktiwiteit gestimuleer. Aan die einde van 1974 sal die O E S O 'n studie stuk publiseer oor die vraag hoe die energieprobleem tussen nou en 1985 opgelos kan word. Die huidige energiekrisis kan ten gevolg hê dat baie vinnig aan kernenergiesentrales gewerk sal moet word ten spyte van die milieu-higiënise besware teen radio-aktiewe afval.

Westerse energiedeskundiges meen dat die nuwe oliepryse die ontwikkeling van alternatiewe energiebronne baie aantreklik maak. Beramings dui daarop dat groot hoeveelhede olie byvoorbeeld uit die skalieneerslae van die Rotsgebergtes in die V S A teen $\$ 8$ per vat geproduseer kan word. Mnr. William Simon van die Amerikaanse kantoor van energiebewaring het aangekondig dat die $1220 \mathrm{~km}$ TransAlaska oliepyplyn waarmee vanjaar begin word, teen die einde van hierdie dekade voltooi sal wees en dat die Amerikaanse olie-invoere tot dan sal toeneem maar daarna geleidelik sal begin afneem. Hy meen dat kernkrag teen 1985 in 10 persent van die V S A se totale energiebehoeftes sal voorsien in vergely king met 1 persent vandag en dat geotermiese en sonenergie teen die 1990's vry algemeen in gebruik sal wees. Verder meen geoloë dat groot hoeveelhede olie en natuurlike gas onder die kuswaters van die V S A lê wat ontwikkel kan word. Amerika beskik oor uraanbronne om grootskaale toe name in die opwekking van elektrisiteit deur kernkrag moontlik te maak. Sommige ekonome meen dat die V S A binne 4 jaar sy energiekrisis in so ' $n$ mate die hoof sal bied dat die groei van die bruto nasionale produk en hoër indiensname dan nie deur'n gebrek aan energie beperk sal word nie. Teen $1985-90$ kan die V S A wat olie betref waarskynlik selfvoorsienend wees. 
Offisiële olieprojeksies plaas Brittanje se olieproduksie uit die Noorsee teen 1980 op tussen 500 en 750 miljoen vate. Internasionale oliemaatskappye beraam die syfer vir 1985 konserwatief op 1100 miljoen. Die bekende oliereserwes in die Noordseegebied mak sowat 2 persent van die bekende wêreldreserwes uit; die Midde-Ooste besit 55 persent, die V S A 7,5 persent en Rusland, Oos-Europa en Sjina saam 16,1 persent.

Alhoewel Japan gelukkig voel oor die feit dat hy nou op die Arabiese lys van begunstigde lande verskyn, word ook naarstiglik na alternatiewe bronne gesoek. Met Sjina is reeds onderhandelings aangeknoop om oliereserwes in Pohaibaai te help ontwikkel.

Die moontlikheid om brandstof te bespaar is groot. Volgens J H Gibbons, direkteur van die V S A se kantoor van energiebewaring kan die V S A binne die volgende twee dekades energieverbruik op vervoer met 50 persent verminder deur middel van die herontwerp van motorvoertuie, benuttig van massavervoer en die verskuiwing van vrag na minder energie-intensiewe metodes.

Omdat Suid-Afrika vir baie jare reeds onder die druk van V V O sanksies staan is enkele maatreëls om boikotte die hoof te bied reeds getref. Die eerste hiervan was om 'n ooreenkoms met Iran aan te gaan om in Suid-Afrika se oliebehoeftes te voorsien. Alhoewel besonderhede oor die ooreenkoms onbekend is, word aanvaar dat die kontrak ' $n$ hele aantal dekades insluit wat deur Iranse investerings in Suid-Afrikaanse olierafinadery-installasies en ander nywerhede gewaarborg word.

Die tweede maatreël was om olie op te berg. Suid-Afrikaanse reserwes teen die lopende gebruikskoers is na skatting genoeg vir sowat 2 jaar se behoeftes.

Verder is ook bekend dat die olie-uit-steenkooleenheid by Sasol wat in 'n klein persentasie van Suid-Afrika se brandstofbehoeftes voldoen in die nabye toekoms uitgebrei gaan word. Daar is ook sprake van 'n groter eenheid wat meeste van die moderne metodes sal inkorporeer.

Suid-Afrika se grootste bate in die huidige krisis is die feit dat ons nog voldoende steenkoolneerslae vir sowat 100 jaar besit. Steenkool is ' $n$ strategiese uitvoerkomoditeit en kan ' $n$ bron van inkomste wees indien Arabiese oliebeperkings Europese en Amerikaanse lande dwing om na steenkool vir die produksie van krag oor te skakel.

'n Deel van Suid-Afrika se oliebehoeftes gaan in die vorm van heruitvoere van bunkerolie vir skepe wat Suid-Afrikaanse hawens besoek. 
Seevervoer kan ernstig benadeel word deur groot beperkings op Suid-Afrikaanse olievoorsiening. 'n Aantal oponthoude het reeds voorgekom aangesien die owerheid slegs bereid is om skeepsmaatskappye met gereelde roetes na Suid-Afrika van olie te voorsien. Rederye wat S A tradisioneel vyandiggesind is, is die ernstigste getref.

Die interessantste ontwikkeling in die jongste tyd is die belangstelling van Westerse nyweraars om deelname in groter eksploitasie van Suid-Afrika se hoëgraad steenkool te bekom. Daar is selfs sprake van 'n aantal olie-uit-steenkool onderhandelings tussen mynhuise, oliemaatskappye en verskillende regerings.

Suid-Afrika se vetkole word hoog aangeslaan as brandstof vir kragsentrales en indien kragsentrales weer van olie na steenkool omgeskakel word om gepulweriseerde steenkool te gebruik kan dit 'n groot vraag na Suid-Afrikaanse vetkool laat onstaan.

In die afgelope maande het 'n aantal internasionele oliemaatskappye ook opsies op grenssteenkoolgebiede geneem waar Suid-Afrikaanse mynhuise geen opsies het nie.

As gevolg van olietekorte in Mosambiek het Portugal in die jongste tyd olie vanaf Angola na Lourenco Marques en Beira laat vloei. In geval sanksies ernstige probleme vir Suid-Afrika sou skep is ' $n$ ooreenkoms met Portugal om olie uit Angola te bekom baie waarskynlik. Terselfdertyd kan aanvaar word dat ook behoorlik omgesien sal word na die oliebelange van Rhodesië wat saam met Suid-Afrika en Portugal die langtermyn stabiliteit van suidelike Afrika beskerm.

Alhoewel Suid-Afrika nie so ernstig deur die huidige olieboikotte getref word nie sal ons bestaande energiebronne met oordeel benut moet word en overpoosd na nuwe bronne gesoek moet word.

\section{SAMEVATTING.}

Toekomstige energie-ontwikkeling dui daarop dat die Arabiese olieprodusente tot die 1980's die energietoneel sal oorheers maar daarna met skerp mededinging op hierdie terrein te doen sal kry.

Die wêreld het as gevolg van die oliekrisis 'n nuwe tydvak van ernstige energienavorsing en van nuwe aanpassings op verskillende terreine binnegegaan.

Die jongste gebeure beklemtoon weereens die feit dat Suid-Afrika alles in sy vermoë moet doen om alternatiewe oliebronne te vind om so vinnig moontlik van die Arabiese bronne onafhanklik te raak. Tot 
dusver het ons sowat R80 miljoen in die oliesoektog spandeer. 91 gate is sonder enige sukses geboor. (In 1973 het die V S A alleen 7539 gate geboor waarvan 90 persent in die sogenaamde "nuwe gebiede" droog was.)

Alhoewel die onderliggende aspekte wat tot die energiekrisis gelei het vir etlike jare reeds bestaan, het die skielike dramatiese ontdekking van die probleem gelei tot vinniger besluitneming ten opsigte van die stappe wat in hierdie verband geneem moet word as wat andersins die geval sou gewees het.

Indien die wêreld sy kennis en tegnologie internasionaal saamspan mag dit wees dat toekomstige geslagte dankbaar sal wees oor die huidige energiekrisis. Op die oomblik word steenkoolkrag, kernkrag, sonkrag en oseaankrag met nuwe verwagtings beskou. Ons staan waarskynlik op die drumpel van opwindende ontdekkings. Die Weste sal elke politieke-, ekonomiese- en tegnologiese maatreël tref om die huidige energiekrisis die hoof te bied.

Al het die Arabiere die olieboikot teen die V S A beindig is dit duidelik dat die energiekrisis nog vir 'n geruime tyd 'n internasionale verskynsel sal wees.

P.U. VIR C.H.O.

D. P. ERASMUS

MAART 1974 